\title{
Air dehumidification by membrane with cold water for manned spacecraft environmental control
}

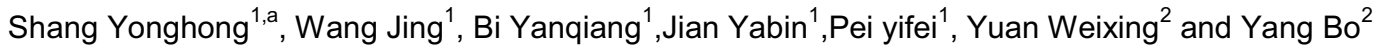 \\ ${ }^{1}$ Beijing Institute of Spacecraft Environmental Engineering, Beijing, China \\ ${ }^{2}$ School of Aeronautic Science and Engineering, Beihang University,Beijing, China
}

\begin{abstract}
The traditional condensation dehumidification method requires additional gas-liquid separation and water recovery process in the manned spacecraft humidity control system, which would increase weight and complexity of systems. A new membrane dehumidification with cold water is proposed, which uses water vapor partial pressure difference to promote water vapor transmembrane mass transfer for dehumidification. The permeability of the membrane was measured and the experimental results agree well with the theoretical calculations. Based on the simulation of dehumidification process of cold water-membrane, the influence of module structure and working condition on dehumidification performance was analyzed, which provided reference for the design of membrane module construct. It can be seen from the simulation and experiments that the cold water-membrane dehumidification can effectively reduce the thermal load of the manned spacecraft.
\end{abstract}

\section{Induction}

Humidity control is takes an important role in Environmental Control and Life Support System for manned space missions. An astronaut will release almost $1.5 \mathrm{~kg} / \mathrm{d}$ moisture by metabolism[1]. High humidity will not only influence the thermal comfort and health, but also is harmful to electronic equipment, which may cause many security problems[2].An active environmental control method of condensing dehumidification has been researched and utilized in many manned spacecraft such as Space Shuttle, ISS and Shenzhou[3]. Warm and humid air is cooled below dew point by Condensing Heat Exchanger(CHX) with humidity and temperature decreasing. The condensate water is absorbed by hydrophilic coating on the surface of CHX fins and is separated from air-water mixture by a mechanical rotary separator under microgravity environment. But CHX requires much energy consumption to cool and reheat air before send back to cabin, and to run air/water separator. Moreover, the reliability and lifespan of the movement assembly may limit the system performance[4].

\section{Membrane dehumidification}

Membrane dehumidification technology is based on the principle that water vapor can transfer through membrane pores by partial pressure difference of water vapor. A novel cold water and

\footnotetext{
${ }^{a}$ Corresponding author: yonghongshang@126.com
} 
membrane assembly for air dehumidification is researched. The membrane dehumidifier is a typical shell-and-tube construct as shown in Figure1. A bundle of hollow fibre membranes is packed in the shell with terminations epoxy sealed to create the tube and shell side. The warm and humid air enters entrance and flows at the shell side, and the water vapor permeates through membrane pores into the tube side, because cold water flows in the tube side bring condensing water away to realize air dehumidification. The water at the tube side cannot leak out from pores because of the hydrophobic nature of membrane. There are no moving parts or electronics within the system.

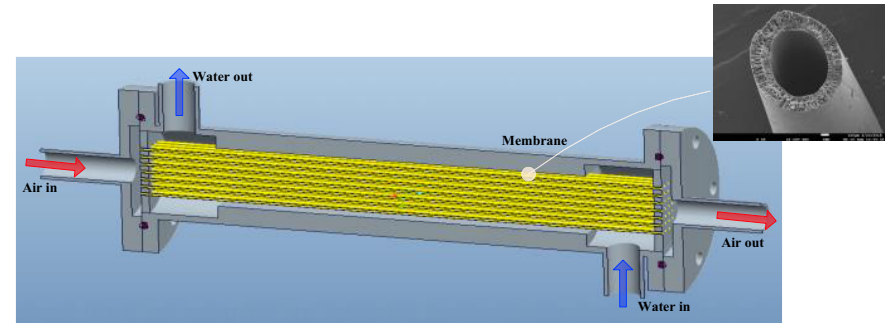

Figure 1. The hollow fibre membrane assembly

Spacesuit Water Membrane Evaporator have been developed by NASA to provide heat rejection capability in Mars[5]. Bundles of Nafion membrane are assembled inside vacuum shell as humidity control subassembly for the Boeing CST-100 Starliner spacecraft[6].A semi-permeable membrane material is used to remove water vapor from humid air. Various materials such as Polyvinylidene Fluoride(PVDF), Polytetrafluoroethylene(PTFE) and Cellulose Acetate(CA) were used and compared.

\section{Methodology}

Dehumidification process is a combination of heat and mass transfer. Heat transfers serially through the thermal boundary layer at the air-side, and then conducted by membranes and transfers through the thermal boundary layer at the water-side. The convective transport boundary layer theory is applicable to the mass transfer as well. The mass transfer resistance of water-side is considered to be negligible, only the mass transfer resistance of air-side should be taken into account.

\subsection{Membrane diffusion}

A kind of hydrophilic-hydrophobic membrane was adopted in this research. The inner layer of membrane is PVDF porous structure of as hydrophobic support. The outer layer of membrane is thin hydrophilic PVA with dense structure. The parameters of material are listed in Table 1.

Table 1. Physical parameters of material

\begin{tabular}{|c|c|c|c|c|}
\hline Layer & Parameter & Symbol & Unit & Value \\
\hline \multirow{4}{*}{ Inner } & Thickness & $\delta_{1}$ & $\mu \mathrm{m}$ & 110 \\
\cline { 2 - 5 } & $\begin{array}{c}\text { Average } \\
\text { pore size }\end{array}$ & $d_{p}$ & $\mu \mathrm{m}$ & 0.15 \\
\cline { 2 - 5 } & Porosity & $\varepsilon$ & - & 0.65 \\
\cline { 2 - 5 } & Tortured & $\tau$ & - & 3 \\
\hline \multirow{3}{*}{ Outer } & Thickness & $\delta_{2}$ & $\mu \mathrm{m}$ & 40 \\
\cline { 2 - 5 } & $\begin{array}{c}\text { Diffusion } \\
\text { coefficient }\end{array}$ & $D_{w s}$ & $\mathrm{~m}^{2} / \mathrm{s}$ & $3.2 \times 10^{-10}$ \\
\hline
\end{tabular}




\begin{tabular}{|l|c|c|c|c|}
\hline & Density & $\rho_{s}$ & $\mathrm{~kg} / \mathrm{m}^{3}$ & 1280 \\
\hline
\end{tabular}

The average pore size of the support layer is $0.15 \mu \mathrm{m}$, which is close to the average molecular free path $(0.09 \mu \mathrm{m})$. According to the diffusion model, the diffusion mechanism of water vapor in the support layer includes Knusson diffusion, viscous flow and molecular diffusion[7,8]. Where $C_{a}=$ $3.203 \times 10^{-4}, v_{v}=20.1, v_{a}=12.7$; $\mathrm{R}$ is the gas constant; $M_{v}$ is the molar mass of water vapor; $M_{a}$ is the molar mass of air; $\mu$ is the kinetic viscosity of water vapor; $p$ and $T$ are the average pressure and temperature in the pores.

$$
\begin{gathered}
D_{K}=\frac{d_{p} \varepsilon}{3 \tau} \sqrt{\frac{8 R T}{\pi M_{v}}} \\
D_{P}=\frac{d_{p}^{2} \varepsilon p}{32 \tau \mu} \\
D_{v a}=\frac{C_{a} T^{1.75}}{p\left(v_{v}^{1 / 3}+v_{a}^{1 / 3}\right)^{2}} \sqrt{\frac{1}{M_{v}}+\frac{1}{M_{a}}}
\end{gathered}
$$

According to the diffusion resistance model, the diffusion coefficient of the support layer is

$$
D_{v m 1}=\frac{1}{1 / D_{K}+1 / D_{v a}}+D_{P}
$$

The diffusion coefficient of water vapor in the outer layer is calculated by the equivalent of the diffusion coefficient of water, where $\rho_{a}$ is air density; $\psi$ is partition coefficient equals to 15 .

$$
D_{v m 2}=\frac{\rho_{s}}{\rho_{a}} \psi D_{w s}
$$

So the total diffusion coefficient of water vapor is

$$
D_{v m}=\frac{\delta_{1}+\delta_{2}}{\delta_{1} / D_{v m 1}+\delta_{2} / D_{v m 2}}
$$

According to above, the diffusion coefficient of water vapor through membrane is $6.28 \times 10^{-6} \mathrm{~m}^{2} / \mathrm{s}$.

\subsection{Convective heat and mass transfer}

According to the similarity theory, the mass transfer can be compared with the convective heat transfer. The relation of the mass transfer number $S h$ and the convective heat transfer number $N u$ will satisfy with the Chilton-Colburn correlation[9], $S h=N u L e^{-1 / 3}$, Where $L e$ is the Lewis number, $L e=\frac{P r}{S c}$; $\operatorname{Pr}$ is the Prandtl number, $\operatorname{Pr}=\frac{\mu c_{p}}{\lambda} ; S c$ is the Schmidt number, $S_{c}=\frac{\mu}{\rho D_{v a}} ; \rho, c_{p}, \lambda$ and $\mu$ are respectively the density, specific heat capacity, thermal conductivity, and dynamic viscosity of humid air.

\subsection{Control equation}

The sensible heat transfer will occur between humid air and cold water, and the temperature of humid air will be decreased. While the moisture content of humid air will decrease because of transmembrane mass transfer of water vapor. Cold water absorbs the sensible heat from warm humid air, while the latent heat will be produced in the process of moisture absorption, so the temperature of cold water will increase.

$$
d Q+r d J=\dot{m}_{w} c_{p w} d t_{w}
$$

The rate of heat and mass transfer will be calculated as follows, where $h_{t}$ and $k_{t}$ are the total heat and mass transfer coefficient.

$$
d Q=h_{t}\left(t_{a}-t_{w}\right) d A
$$




$$
d J=\rho_{a} k_{t}\left(\omega_{a}-\omega_{w}\right) d A
$$

\subsection{Membrane permeability experiments}

In order to determine the diffusion coefficient of water vapor through membrane by experiment, a shell-and-tube membrane assembly was made, which was filled with six hollow fibre membrane tubes and with the total membrane area of $19.1 \mathrm{~cm}^{2}$. The micro-flow test bed was built, including circulating water and gas loop to provide $10 \mathrm{~mL} / \mathrm{min}$ water flow and $10 \mathrm{~L} / \mathrm{min}$ air flow. The experimental diffusion coefficient of water vapor in membrane was $6.44 \times 10^{-6} \mathrm{~m}^{2} / \mathrm{s}$. The experiment results were consistent with the theoretical model result of $6.28 \times 10^{-6} \mathrm{~m}^{2} / \mathrm{s}$, verifying the reliability of the theoretical model.

\section{Dehumidification performance analyses}

\subsection{Flow form}

The performance analysis of the counter-flow or cross-flow of the shell-and-tube heat exchangers is carried out. The convective mass transfer resistance of the counter flower is larger than that of the cross-flow at the same Reynolds number as shown in Figure 2. However, the heat transfer resistance of counter-flower is also larger than cross-flow as shown in Figure 3. When the Reynolds number is 300 , the heat transfer resistance of counter-flow $\left(0.0457 \mathrm{~m}^{2} \mathrm{~K} / \mathrm{W}\right)$ is 6 times of cross-flow $(0.0076$ $\left.\mathrm{m}^{2} \mathrm{~K} / \mathrm{W}\right)$ and the mass transfer resistance of counter-flow $(80 \mathrm{~s} / \mathrm{m})$ is 1.8 times of cross flow $(44.8 \mathrm{~s} / \mathrm{m})$. In order to prevent the dewing on fibre outer surface as result of the faster heat transfer rate than the mass transfer, the form of counter-flow and the cylindrical structure of shell are adopted. This configuration is also more favourable for the flow uniformity.

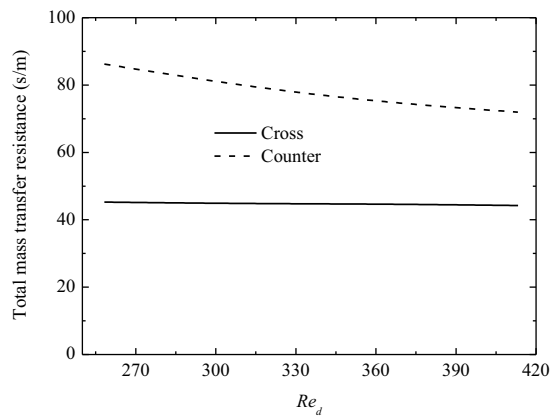

Figure 2. Comparison of mass transfer resistance

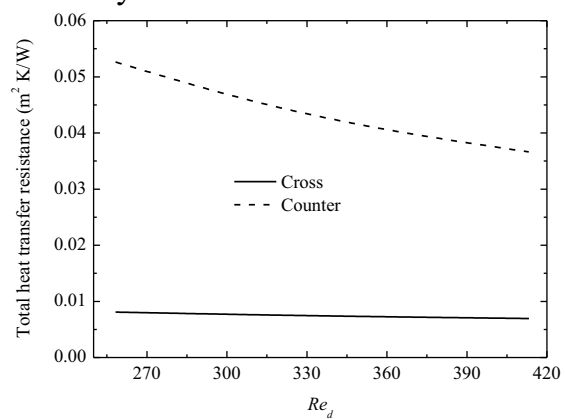

Figure 3. Comparison of heat transfer resistance

\subsection{Assembly structure design}

The membrane assembly was designed for the quantity of membrane tubes and the inner diameter of shell with the target dehumidification rate of $400 \mathrm{~g} / \mathrm{h}$. To increase the quantity of tubes can enlarge the mass transfer area and reduce the shell side circulation area, so that the convective mass transfer coefficient of shell side will increase, and the dehumidification rate will increase too. To reduce the shell inner diameter can increase the convective mass transfer coefficient of the shell-side, thereby the dehumidification rate will increase. Improve the mass transfer performance will enhance the heat transfer performance at the same time, which will lead to the relative humidity of the outlet air increase and the risk of water condensation on the tube surface.

According to the typical operating conditions of the manned spacecraft humidify control requirements, the inlet air temperature is $26^{\circ} \mathrm{C}$ and the relative humidity is $60 \%$, the inlet cold water temperature is $5^{\circ} \mathrm{C}$, the flow rate of air and cold water are both $0.1 \mathrm{~kg} / \mathrm{s}$ and the tube length is $300 \mathrm{~mm}$. The design range of the membrane tube quantity and shell inner diameter is calculated as shown in 
Figure 4. In order to achieve dehumidification rate is more than $400 \mathrm{~g} / \mathrm{h}$, the reasonable quantity of membrane tube and shell inner diameter should be designed below the solid line and above the dotted line. On the other hand, the smaller shell diameter, the greater pressure drops on the air-side as shown in Figure 5.

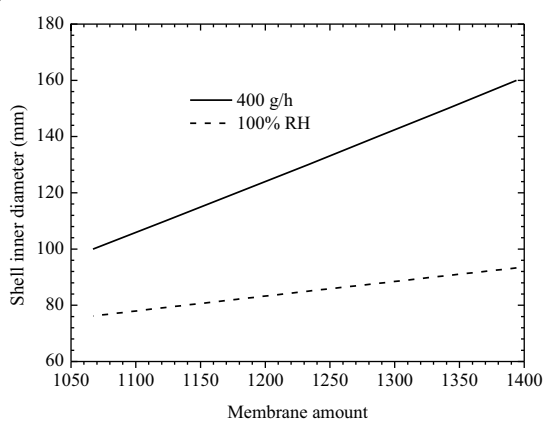

Figure 4. Design range(high-humidity)

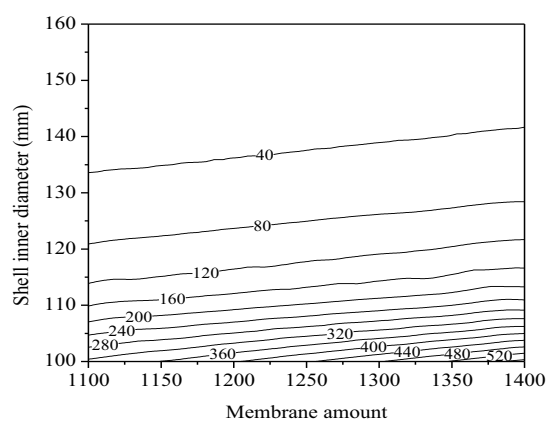

Figure 5. Air-side pressure drop (high-humidity)

Under the operating condition that the inlet air temperature is $22.5^{\circ} \mathrm{C}$ and the relative humidity is $50 \%$, the tube length is $400 \mathrm{~mm}$, and the other condition as above. The design range of tube quantity and shell inner diameter is calculated as shown in Figure 6. The quantity of tubes required in the low humidity condition is significantly increased compared with Figure 4, and the inner diameter of the shell is also increased. The design range under low humidity conditions is significantly narrower, that is to ensure dehumidification rate, and the risk of condensation is increasing. The smaller shell diameter, the greater pressure drops on the air-side as shown in Figure 7.

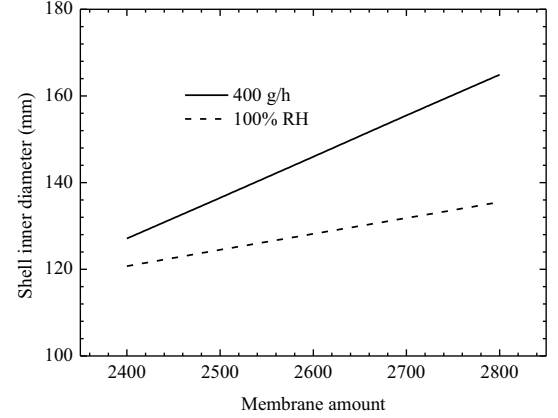

Figure 6. Design range (low-humidity)

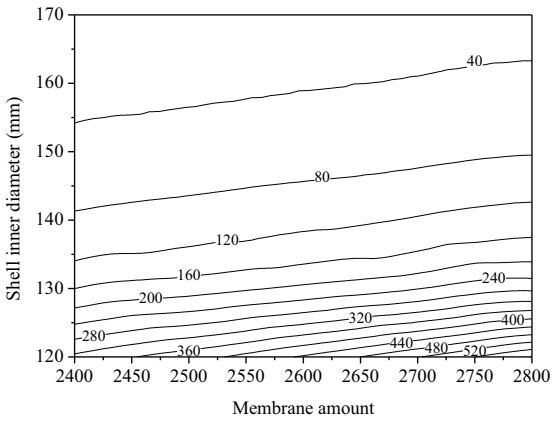

Figure 7. Air-side pressure drop (low-humidity)

\subsection{Operating condition}

When the manned cabin conditions of temperature and humidity are keep constant, the dehumidification rate is adjusted by changing the air flow and temperature of cold water. The greater the air flow, the greater the mass transfer coefficient on the air side, the easier moisture content of air is maintained at higher value, and the greater mass transfer potential difference, both of which will contribute to the dehumidification performance. And on the other hand, the lower temperature of cold water can effectively reduce partial pressure of water vapor, thereby improving the dehumidification performance.

Figure 8 shows the design results of different dehumidification performance of operating conditions, where the air temperature and humidity are maintained at $26{ }^{\circ} \mathrm{C}$ and $60 \%$, cold water flow is $0.1 \mathrm{~kg} / \mathrm{s}$. In order to maintain the dehumidification capacity, the air flow needs to be enlarged when the temperature of cold water increases. Since the relationship between partial pressure of water vapor and cold water temperature is non-linear, and the magnitude of partial pressure of water vapor will increase more and more with the water temperature increases, which will result in a sharp decrease in mass transfer potential difference, so the increase extent of air flow will be more and more. 
From the above simulation analysis, the membrane assembly can meet the dehumidification requirements even the temperature of cold water rose to $10^{\circ} \mathrm{C}$. Compared with condensing dehumidification's cold water operating temperature is $5^{\circ} \mathrm{C}$, cold water-membrane dehumidification system has lower requirements on the cooling capacity, which has better thermodynamic properties.

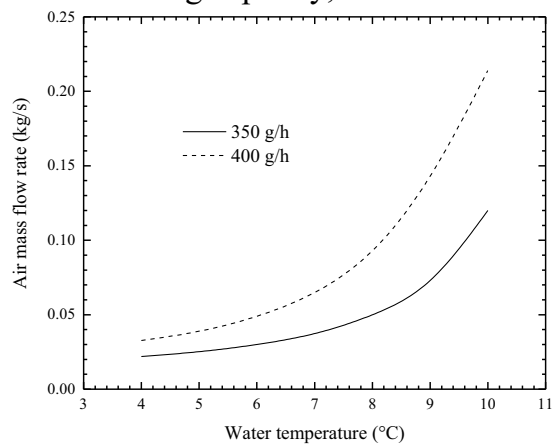

Figure 8. Operating condition design under different dehumidification demands

\section{Results and discussion}

A novel cold water-membrane dehumidification method is proposed for manned spacecraft. The heat and mass transfer model was established for the cold water-membrane dehumidification process, and the membrane permeability was measured by experiment. The process of cold water-membrane dehumidification assembly was simulated and the counter-flow form was determined. The structure and operating conditions were designed for certain dehumidification requirements. Compared with condensation dehumidification, cold water-membrane dehumidification has advantages:(1) achieves water recovery without additional gas-liquid separation processes;(2) assembly consisting of polymer materials are lighter in weight;(3) has better thermodynamic properties.

\section{References}

1. Huang JR and Fan HL. Numerical simulation of the thermal and humid environment in manned spacecraft habitation cabin. Chinese Space Sci Technol 2004; 24: 7-13

2. Michael Izenson1, Weibo Chen. Evaporative Cooling and Dehumidification Garment for Portable Life Support Systems. 43rd International Conference on Environmental Systems, July14-18, 2013.

3. Westheimer D., Tuan G. Active Thermal Control System Considerations for the Next Generation of Human Rated Space Vehicles. AIAA 10-13 January 2005

4. David W., Jason D., Gregory G. International Space Station Environmental Control and Life Support System Status for the Prior Year:2010-2011. 42 ${ }^{\text {nd }}$ International Conference on Environmental Systems. 2012

5. Tony JR, John WS, Grant B. Performance of a Water Recirculation Loop Maintenance Device and Process for the Advanced Spacesuit Water Membrane Evaporator. AIAA, 2013

6. Christie Iacomini, Josh Hecht, Jim Harrell, John Lumpkin. Qualification of the Boeing Starliner humidity control subassembly, 2016-322

7. Tomaszewska M., Gryta M., Morawski A. Mass Transfer of $\mathrm{HCl}$ and $\mathrm{H}_{2} \mathrm{O}$ across the Hydrophobic Membrane During Membrane Distillation. Journal of Membrane Science, 2000, 166(2): 149-157

8. Zhang L.-Z., Huang S.-M., Pei L.-X. Conjugate Heat and Mass Transfer in a Cross-Flow Hollow Fibre Membrane Contactor for Liquid Desiccant Air Dehumidification. International Journal of Heat and Mass Transfer, 2012, 55(25): 8061-8072

9. Zhang L.-Z., Li Z.-X., Zhong T.-S., et al. Flow Maldistribution and Performance Deteriorations 
in a Cross Flow Hollow Fibre Membrane Module for Air Humidification. Journal of Membrane Science, 2013, 427: 1-9 